This item was submitted to Loughborough's Research Repository by the author.

Items in Figshare are protected by copyright, with all rights reserved, unless otherwise indicated.

\title{
Evaluation of the short and medium term use of insoles for personalised footwear
}

PLEASE CITE THE PUBLISHED VERSION

http://dx.doi.org/10.1080/19424280.2011.575816

PUBLISHER

(C) Taylor and Francis

VERSION

AM (Accepted Manuscript)

LICENCE

CC BY-NC-ND 4.0

REPOSITORY RECORD

Salles, Andre S., Diane E. Gyi, and Stephanie E. Forrester. 2019. "Evaluation of the Short and Medium Term Use of Insoles for Personalised Footwear". figshare. https://hdl.handle.net/2134/9026. 
This item was submitted to Loughborough's Institutional Repository (https://dspace.lboro.ac.uk/) by the author and is made available under the following Creative Commons Licence conditions.

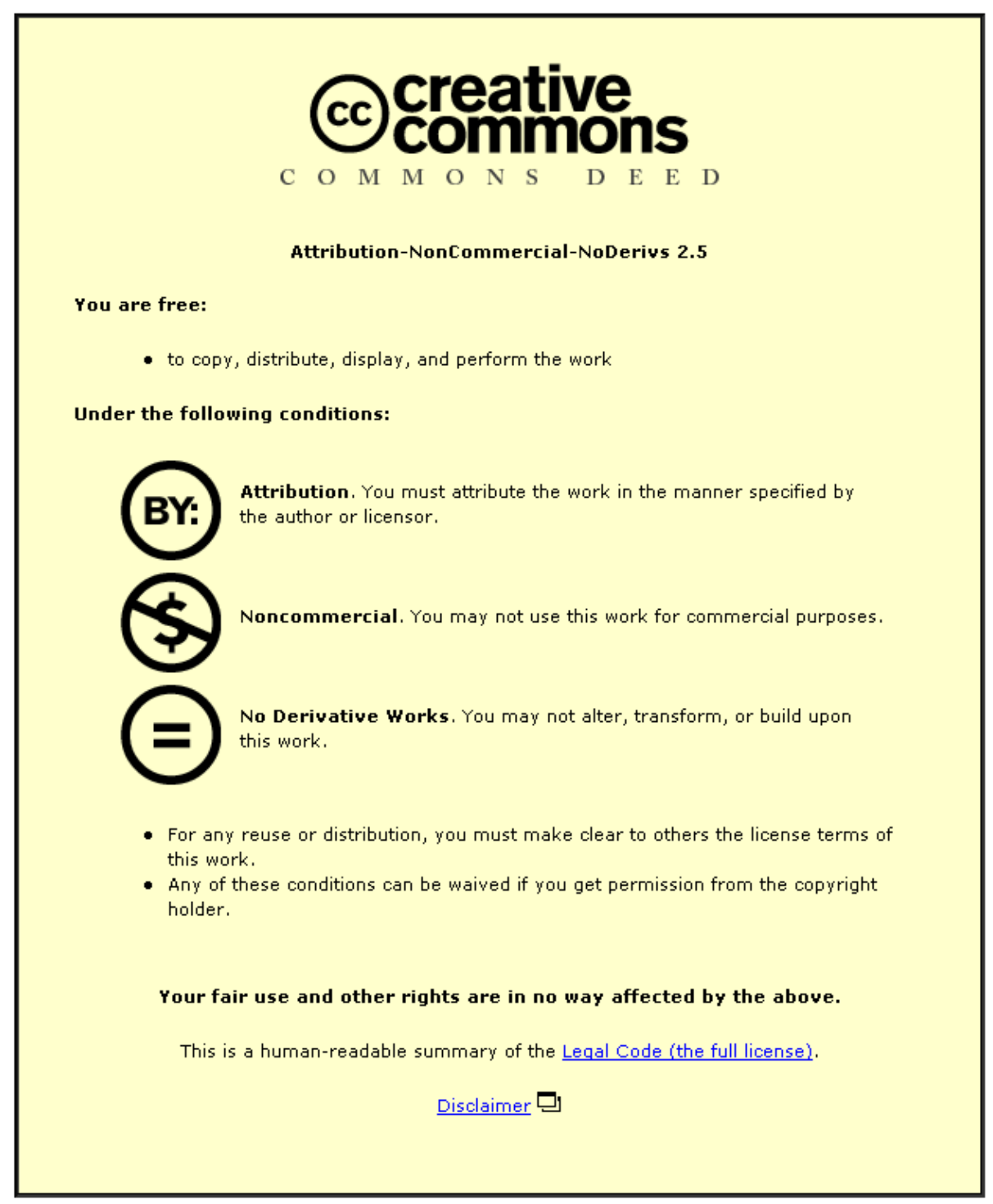

For the full text of this licence, please go to: http://creativecommons.org/licenses/by-nc-nd/2.5/ 


\title{
EVALUATION OF THE SHORT AND MEDIUM TERM USE OF INSOLES FOR PERSONALISED FOOTWEAR
}

\author{
André S. Salles ${ }^{1}$, Diane E. Gyi ${ }^{1}$ and Stephanie E. Forrester ${ }^{2}$ \\ ${ }^{1}$ Loughborough Design School, Loughborough University, Loughborough, United Kingdom \\ ${ }^{2}$ Sports Technology Institute, Loughborough University, Loughborough, United Kingdom
}

\section{INTRODUCTION}

The personalisation of footwear can be beneficial for different population groups, including older people, individuals with foot pathologies or abnormalities and runners. For runners in particular, footwear personalisation has the potential to offer four main advantages: optimum fit, improved comfort perception, improved performance (by altering lower limb alignment to reduce muscle activity) and reducing injury risk through personalisation of cushioning and support requirements.

Additive manufacturing (AM) technology has potential for making footwear personalisation economically feasible due to its geometric freedom, tool-less capability and direct manufacture from CAD models. However, it is not known how personalised footwear affects discomfort and biomechanics following short and medium term use.

The main objective of this research was to evaluate the short and medium term use of personalised insoles in terms of discomfort and lower extremity biomechanics.

\section{METHODS}

Thirty eight healthy recreational runners (18 males and 20 females) were recruited. A single-blind paired samples design was employed with two experimental conditions, personalised (PERS) and control (CTRL). Participants were paired according to: gender, age, body mass index and running $\mathrm{km}$ per week, enabling 19 matched pairs. The participants had both feet scanned a using a 3D laser scanner (RealScan USB 200), 15 anthropometric measurements of the foot taken, and were allocated to one of the two experimental conditions. The PERS condition consisted of a pair of trainers (NB-757) fitted with personalised insoles that were designed (Geomagic Studio software) from the foot scans to match the exact plantar geometry of the individuals' foot. The CTRL consisted of the same trainers, fitted with a pair of insoles designed from scans of the experimental trainers' original insoles. Both conditions were manufactured using the same material (DuraForm PA), thickness (2 mm) and AM technology (laser sintering). Thus, the only difference between conditions was insole geometry. The process of capturing and measuring the foot, designing and manufacturing the insoles using AM is described elsewhere (Salles and Gyi 2010).

Participants attended laboratory sessions at the start of the study (month 0), halfway (month 1.5) and at the end (month 3 ) for measurements of discomfort and lower extremity biomechanics. Six aspects of shoe discomfort (overall, forefoot, midfoot, heel, arch and fit) were assessed using $150 \mathrm{~mm}$ visual analogue scales (Mundermann et al. 2002) ranging from 'most comfortable condition imaginable' to 'not comfortable at all'. The biomechanical variables analysed 
were: 3-D kinematics of the knee and ankle (Vicon MX System) and vertical ground reaction force (9281CA Kistler Inst.) during 5 running trials at $2.78 \mathrm{~m} / \mathrm{s}( \pm 5 \%)$ with speed controlled using electronic timing gates (SmartSpeed). For the purpose of normalising the data, at the start of study the biomechanics for all participants were measured using the original insoles of the experimental trainers. Participants were instructed to wear the trainers with the AM insoles every time they ran and to complete an activity diary throughout the 3-month period.

\section{RESULTS AND DISCUSSION}

From the 38 participants recruited, 7 discontinued, leaving 13 pairs that completed the study. Paired samples Student's $t$ tests indicated significantly lower $(\mathrm{p}<0.05)$ discomfort ratings in the midfoot, heel and fit for PERS versus CTRL at month 0 and month 3. In addition, all other discomfort ratings showed reduced discomfort for PERS compared to CTRL over the 3-month period. Arch discomfort was rated highest of the six aspects, indicating that non-weight bearing scans may not have been the ideal position to capture the arch. On the other hand, heel cup design in the PERS proved to be beneficial, possibly by giving a sensation of good fit.
At foot strike, runners in the PERS condition demonstrated a less dorsiflexed ankle that may be related to a significant reduction in mean loading rate and lower impact force peak (Table 1). The PERS also showed reduced maximum rearfoot eversion. No significant differences were found in the active force peak or knee kinematics over the 3-month period.

\section{CONCLUSION}

The personalised insole was more comfortable over short and medium term use, especially in the midfoot, heel and fit aspects. Most of the biomechanical differences between the two insoles occurred at the ankle joint and during the impact phase of ground contact, with the personalised insole showing reduced impact peak, mean loading rate, ankle dorsiflexion at foot strike and maximum rearfoot eversion. These results support the potential benefits of using personalised insoles for running over sustained periods of at least 3 months.

\section{REFERENCES}

Mundermann, A. et al. (2002). Gait Posture, 16, 38-45.

Salles, A.S. and Gyi, D.E. (2010). In Advances in Human Factors, Ergonomics, and Safety in Manufacturing and Service Industries. Taylor \& Francis: CRC Press, 355-366.

Table 1. Biomechanical data.

\begin{tabular}{|c|c|c|c|c|c|c|}
\hline \multirow{2}{*}{ Parameter } & \multicolumn{2}{|c|}{ Month 0} & \multicolumn{2}{|c|}{ Month 1.5} & \multicolumn{2}{|c|}{ Month 3} \\
\hline & PERS & CTRL & PERS & CTRL & PERS & CTRL \\
\hline $\begin{array}{l}\text { Ankle dorsiflexion } \\
\text { at footstrike }\left({ }^{\circ}\right)\end{array}$ & $-1.44 \pm 2.50^{*}$ & $0.48 \pm 0.73$ & $-0.15 \pm 2.77$ & $1.82 \pm 3.86$ & $-1.30 \pm 5.50$ & $1.62 \pm 4.20$ \\
\hline $\begin{array}{l}\text { Maximum rearfoot } \\
\text { eversion }\left({ }^{\circ}\right)\end{array}$ & $-0.77 \pm 1.30$ & $-0.02 \pm 0.22$ & $-2.07 \pm 2.00 *$ & $0.57 \pm 2.08$ & $-1.93 \pm 2.80$ & $-0.36 \pm 1.66$ \\
\hline $\begin{array}{l}\text { Impact peak } \\
(\%)\end{array}$ & $-5.36 \pm 7.85$ & $-3.38 \pm 10.86$ & $2.36 \pm 7.32$ & $7.58 \pm 16.38$ & $3.39 \pm 8.72$ & $10.98 \pm 18.19$ \\
\hline $\begin{array}{l}\text { Mean loading rate } \\
(\%)\end{array}$ & $-20.54 \pm 14.39 *$ & $-9.57 \pm 14.96$ & $-5.31 \pm 13.51$ & $4.61 \pm 24.61$ & $-5.54 \pm 15.24 *$ & $5.12 \pm 23.36$ \\
\hline
\end{tabular}

Data normalised within individuals: positive values indicate increases and negative values reductions compared to the original insoles. * Significant differences between PERS and CTRL $(\mathrm{p}<0.05)$. 